\title{
CONNECTIONS MADE BY TRANSPLANTS TO THE CEREBRAL CORTEX OF RAT BRAINS DAMAGED IN UTERO ${ }^{1}$
}

\author{
M. K. FLOETER AND E. J. JONES ${ }^{2}$ \\ James L. O'Leary Division of Experimental Neurology and Neurological Surgery nd McDonnell Center for Studies of Higher \\ Brain Function, Washington University School of Medicine, Saint Louis, Missouri 63110
}

Received March 29, 1983; Revised July 12, 1983; Accepted August 2, 1983

\begin{abstract}
Homografts consisting of pieces of neocortex or dissociated cortical cells were transplanted from fetal rats into the cortex of newborn, microcephalic hosts. The cortex of the hosts lacked cells of the superficial layers, as a result of prenatal administration of a cytotoxic drug methylazoxymethanol. Grafts exhibited an internal organization with a tendency to form a molecular layer, and alternating cell and fiber zones, although these were not consistently oriented with respect to the host cortex. Both pyramidal and nonpyramidal cells survived. Some grafts were shown to rcceive callosal connections. Axonal outgrowth from transplanted neurons to several host brain areas was demonstrated with retrograde tracers. Outgrowth occurred not only to the contralateral cortex, in which the host's own callosal projection was deficient, but also to the thalamus and spinal cord, in which the host projection was intact. Thus, grafted fetal cortex is capable of making connections in the methylazoxymethanol-damaged host, but the pattern of connections made is not influenced by host deficiencies.
\end{abstract}

When a rat has been exposed to the cytotoxic drug methylazoxymethanol (MAM) during fetal life its cerebral cortex at maturity lacks neurons of the latest born layers (Johnston and Coyle, 1979; Jones et al., 1982). Nevertheless, those cells which remain send axons to appropriate brain regions; thalamic afferents also enter the somatosensory cortex and, despite the absence of most of their usual targets, terminate in their characteristic somatolopic order; those projections which originate largely from cells of the missing layers, for example, the corpus callosum, are greatly diminished (Jones et al., 1982). Thus, it appears that the cortex of a MAM-treated rat does not undergo adaptive changes in cortical connectivity, that is, surviving cortical cell populations do not compensate for missing cells by making uncharacteristic projections. Instead, the normal pattern of cortical connectivity is maintained for those neurons that survive, and elements of connectivity usually provided by the missing cells are lacking. We wished, therefore, to examine the possibility of restoring missing aspects of cortical connectivity. These attempts to "reconstitute" the microcephalic, MAM-treated cortex exploited the

\footnotetext{
1 This work was supported by Grants NS15070 and GM07200 from the National Institutes of Health, United States Public Health Service. We thank Ms. Bertha McClure and Mr. William Kraft for their technical assistance.

${ }^{2}$ To whom all correspondence should be addressed.
}

recognized capacity of neonatal cortex to accept homografts (Jaeger and Lund, 1980a).

Pieces of embryonic brain can survive transplantation into the brains of newborn (LeGros Clark, 1940; Das, 1975; Lund and Hauschka, 1976; Das et al., 1980; Schmidt et al., 1981) or adult (Bjorkland et al., 1976; Perlow et al., 1979) mammals. Transplants can provide a remarkable degree of functional recovery in some cases of genetic deficiency (Gash et al., 1980; Krieger et al., 1982 ) or brain lesions (Bjorkland nd Stenevi, 1979; Perlow et al., 1979; Dunnett et al., 1981) by providing chemical substances which the host brain is incapable of synthesizing. However, the long-term survival of a transplant may depend on the formation of successful connections with the host brain (Das, 1982).

The factors that govern connection formation between graft and host brains are not known. Afferent innervation of a graft can show a degree of specificity, especially when tissue is transplanted to a location approximating its normal position (Jaeger and Lund, 1980a; Lund and Harvey, 1981; Floeter et al., 1982; Smith and Ebner, 1982). In many cases, however, grafts are innervated by axons from the local region rather than those appropriate for the grafted tissue (Oblinger et al., 1980; Jaeger and Lund, 1980b). In all cases the relative maturity of host afferents at the time of grafting probably also plays some role in determining whether effective afferent innervation will occur, although there is evidence that embryonic 
transplants can promote axonal growth from mature host neurons (Kromer et al., 1980).

Whether grafted neurons can actively choose a set of host target neurons appropriate for them is unclear. When some specific pathways are lesioned, axons from grafts clearly can grow preferentially into the denervated areas (Bjorklund and Stenevi, 1977; Lewis and Cotman, 1982). Moreover, physiological and behavioral evidence suggests the capacity functionally to repopulate appropriate synaptic sites (Dunnett et al., 1982; Low et al., 1982). Yet there is no direct evidence which suggests that graft neurons are expressing an intrinsic preference rather than merely occupying the only available target sites. To examine this question, grafted neurons must be given an opportunity to choose among several target sites, as would occur in a developing brain, for example. To date such experiments have been carried out only with transplants to heterotopic locations; in these, grafted neurons do make many inappropriate connections (e.g., Oblinger and Das, 1982). Whether a piece of transplanted cortex will send axons to appropriate cortical target sites when grafted to a cortical location has not been fully determined. The MAM-treated cortex, which lacks certain cell populations but is just beginning to receive its afferent innervation at birth, offers the opportunity to examine the potential for the establishment of appropriate innervation of a graft made to a normal position but one which is severely compromised.

\section{Materials and Methods}

Animals and surgery

The rats used in this study were the progeny of Wistar rats bred in our colony. The day on which spermatozoa were present in vaginal smears was termed embryonic day zero (E0). Fetuses that were to become hosts were treated with methylazoxymethanol acetate (MAM, Sigma) on E15 or E16 via a single intraperitoneal injection of $6.0 \mathrm{mg}$ in $0.6 \mathrm{ml}$ of normal saline into the pregnant female. After birth they received grafts on the first or second postnatal day. Donor fetuses were labeled with tritiated thymidine (specific activity $20 \mathrm{Ci} / \mathrm{mmol}$; New England Nuclear) on E14 or E15, 2 to 3 days prior to grafting at $\mathrm{E} 17$, via a single intraperitoneal injection into the pregnant female in doses ranging from $0.5 \mathrm{mCi}$ to 3.0 $\mathrm{mCi}$ in $0.5 \mathrm{ml}$ of normal saline.

Transplants were of two types: solid grafts or suspension grafts. Forty-one pups from six litters received solid grafts. The grafting procedure was similar to that of Lund and Hauschka (1976). The pregnant female was anesthetized with chloral hydrate and the lower part of the body immersed in a $37^{\circ} \mathrm{C}$ saline bath so that living donor fetuses could be removed individually from the uterus as needed. Fetal brains were rapidly removed to a dish of Hamm's F-10 medium (GIBCO) on ice. The vascular pattern was used for identification of presumptive parietal cortex, assuming that fetal cortical regions bear the same relationship to the middle cerebral artery as in the adult (Welker, 1971). Strips of cortex, approximately 200 to $300 \mu \mathrm{m}$ wide and 0.5 to $1 \mathrm{~mm}$ long, were cut out with a razor blade and sucked into a micropipette with a tip diameter of approximately $300 \mu \mathrm{m}$ which was attached via fine tubing to a syringe filled with medium. Host pups were anesthetized by hypothermia, and a bone flap was raised over one hemisphere by slipping the bevel of a hypodermic needle under the coronal suture. The cortex at this level in the adult includes the sensorimotor areas. After incising the meninges, the micropipette tip was lowered at a $45^{\circ}$ angle into the host cortex until its tip was buried and the cortical graft was gently ejected.

Twenty-six rats from five litters received grafts of cell suspensions. Suspensions were prepared by incubating pieces of fetal cortex in a glucose-salt solution lacking divalent cations (Puck et al., 1958) for $20 \mathrm{~min}$ at $40^{\circ} \mathrm{C}$ and triturating with a fire-polished Pasteur pipette. Suspensions containing approximately $10^{5}$ viable cells per microliter, as determined by trypan blue exclusion (Paul, 1975), were injected into the host cortex from a micropipette with a tip diameter of approximately $200 \mu \mathrm{m}$ in a fashion similar to that described for solid grafts. Although the injection volumes varied from 1 to $10 \mu \mathrm{l}$, quantitation of the number of cells injected was not possible since there was significant leakage back along the pipette.

Rats receiving grafts were allowed to survive for varying periods up to 6 months.

\section{Histological methods}

Three retrograde tracers were used to examine whether axons of grafted neurons grew into the host brains. Table I lists the tracer, or combination of tracers, injection sites, and ages of each animal with a confirmed graft studied in this way.

1. HRP. One-tenth microliter of $50 \%$ horseradish peroxidase (HRP, Sigma, type VI) dissolved in saline was injected into contralateral cortex, thalamus, or spinomedullary junction of the host. After a survival of $24 \mathrm{hr}$, the animals were perfused with a mixture of phosphatebuffered $1 \%$ paraformaldehyde and $2.5 \%$ glutaraldehyde. Frozen sections were processed according to the methods of De Olmos et al. (1978). This procedure at the survival period used is adequate to visualize maximal anterograde labeling of host fibers within host brain regions following cortical and thalamic injections (M. K. Floeter and E. G. Jones, unpublished observations).

2. Fast blue. One-tenth to one-half microliter of $5 \%$ aqueous fast blue (FB, Illing, Gmbh, Germany) was injected into the thalamus or spinal cord of the host, sometimes in combination with another tracer in a second site (Table I). Following a survival ranging from 4 days to 1 week, the animals were perfused with phosphate-buffered $4 \%$ paraformaldehyde. Brains were cut into slabs approximately $3 \mathrm{~mm}$ thick, soaked in $30 \%$ sucrose overnight, sectioned at $40 \mu \mathrm{m}$ on a freezing microtome, and immediately mounted on slides. These were examined with epifluorescence using a Leitz Dialux 20 microscope.

3. Nuclear Yellow. Volumes of $0.5 \mu \mathrm{l}$ of $2 \%$ aqueous Nuclear Yellow (NY; Bentivoglio et al., 1980) were injected into the spinomedullary junction of two host rats which had received injections of FB 4 days earlier. Twelve hours later animals were perfused and prepared as described for FB.

In two cases the tracers HRP and FB were combined, 
TABLE I

Summary of retrograde labeling experimenls in unimals with grafls confirmed by autoradiography

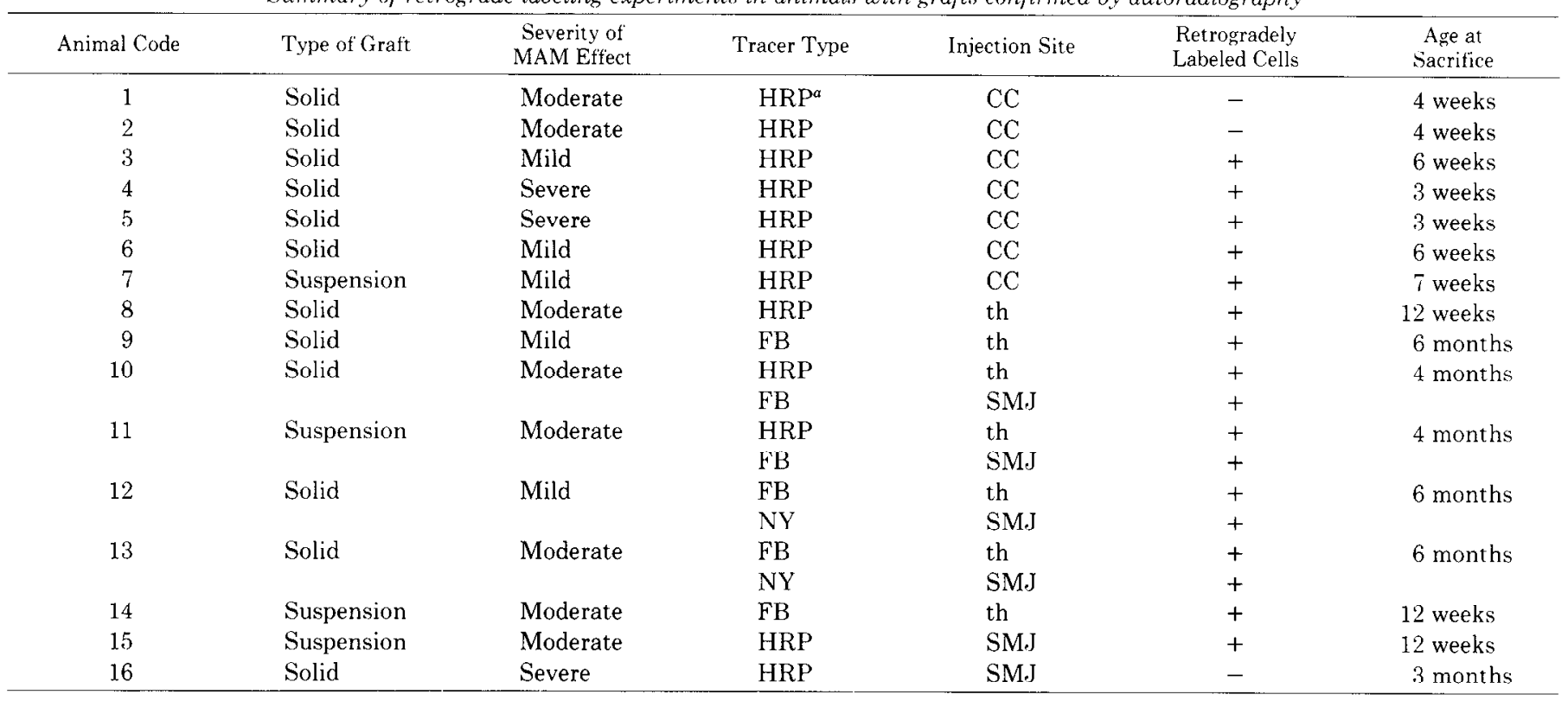

${ }^{a}$ HRP, horseradish peroxidase; FB, fast blue; NY, Nuclear Yellow; CC, contralateral cortex; th, thalamus; SMJ, spinomedullary junction.

but it was found that the glutaraldehyde necessary for adequate demonstration of the $\mathrm{HRP}$ reaction product greatly diminished the FB fluorescence.

In all animals used for the tracing of connections, alternate sections were mounted on gelatin-subbed slides, defatted in chloroform and alcohol, dipped in Kodak NTB2 emulsion, and allowed to expose at $4^{\circ} \mathrm{C}$ for periods of 4 weeks to 8 months depending on the dose of tritiated thymidine. Slides were developed in Kodak D19 developer, fixed with Kodak Ektaflo, and counterstained with thionin.

The histological organization of grafts was examined in Nissl and Luxol Fast Blue-stained sections of eight paraffin-embedded brains. The morphology of cells within grafts was studied in 10 brains stained by the Golgi-Cox (Van der Loos, 1956) or Golgi-Kopsch (Rethelyi, 1972) methods.

\section{Results}

MAM effects. Although there was variability in the extent of cortical damage produced by the injection of MAM, all rats with successful grafts showed a thinned cerebral cortex and attenuated corpus callosum as described by Jones et al. (1982). Many rats had only layers $\mathrm{V}$ and VI surviving (severe effect), but some had surviving layer IV cells (moderate effect) and two litters had cells of layers III and II surviving as well (mild effect).

Graft survival. Upon initial histological examination, structures which appeared to be grafts were seen in 27 of the 41 rats receiving solid grafts and in 16 of the 26 rats receiving suspension grafts. Six solid and four suspension grafts stained by the Golgi method could not be confirmed by autoradiography. Fifteen solid grafts and 10 suspension grafts were confirmed by autoradiography, meaning that a very large proportion of cells showed dense nuclear labeling by $\left[{ }^{3} \mathrm{H}\right]$ thymidine in autoradiographs (Fig. 1). Twelve apparent grafts were rejected because of too light labeling or the labeling of too few cells. We will only present the connections of confirmed grafts in this paper, although the results from the remaining unconfirmed grafts are consistent with these.

Cellular organization. The grafts took on a variety of shapes, sizes and positions. Parts of solid grafts frequently protruded into the lateral ventricle or overlay the pia mater (Fig. 2). In a single section such a graft might appear to be totally contained within the ventricle or outside the pia, but examination of serial sections usually demonstrated that some part of the graft lay within the substance of the host cortex. Regions of continuity were not marked by scar formation nor glial proliferation, although a region of low neuronal cell density resembling a molecular layer often separated graft and host. In a small number of cases, such as the small solid graft in Figure 3B, the boundaries of the graft could only be determined in autoradiographs. Autoradiographs of all solid grafts showed that graft cells remained as a separate cluster and did not disperse throughout the host brain.

When suspensions of cells were grafted, transplanted neurons usually reaggregated into several clumps attached either to the cortical surface, flattened both outside and inside the pia mater (Fig. $3 A$ ), or attached to the cortical white matter and hanging into the lateral ventricle (Fig. $5 A$ ). In one animal, however, some aggregates of graft cells were completely contained within the host cortex and striatum. Large aggregates of several hundred previously dissociated cells were usually well delineated from host cortex by an area of low cell density. In some cases, this was the host's own molecular layer. Aggregates consisting of small numbers of previously dissociated cells (often fewer than 12) could only be identified from autoradiographs since there was often no clear delineation between graft cells and host cells. For this reason, Golgi material from four animals was not 


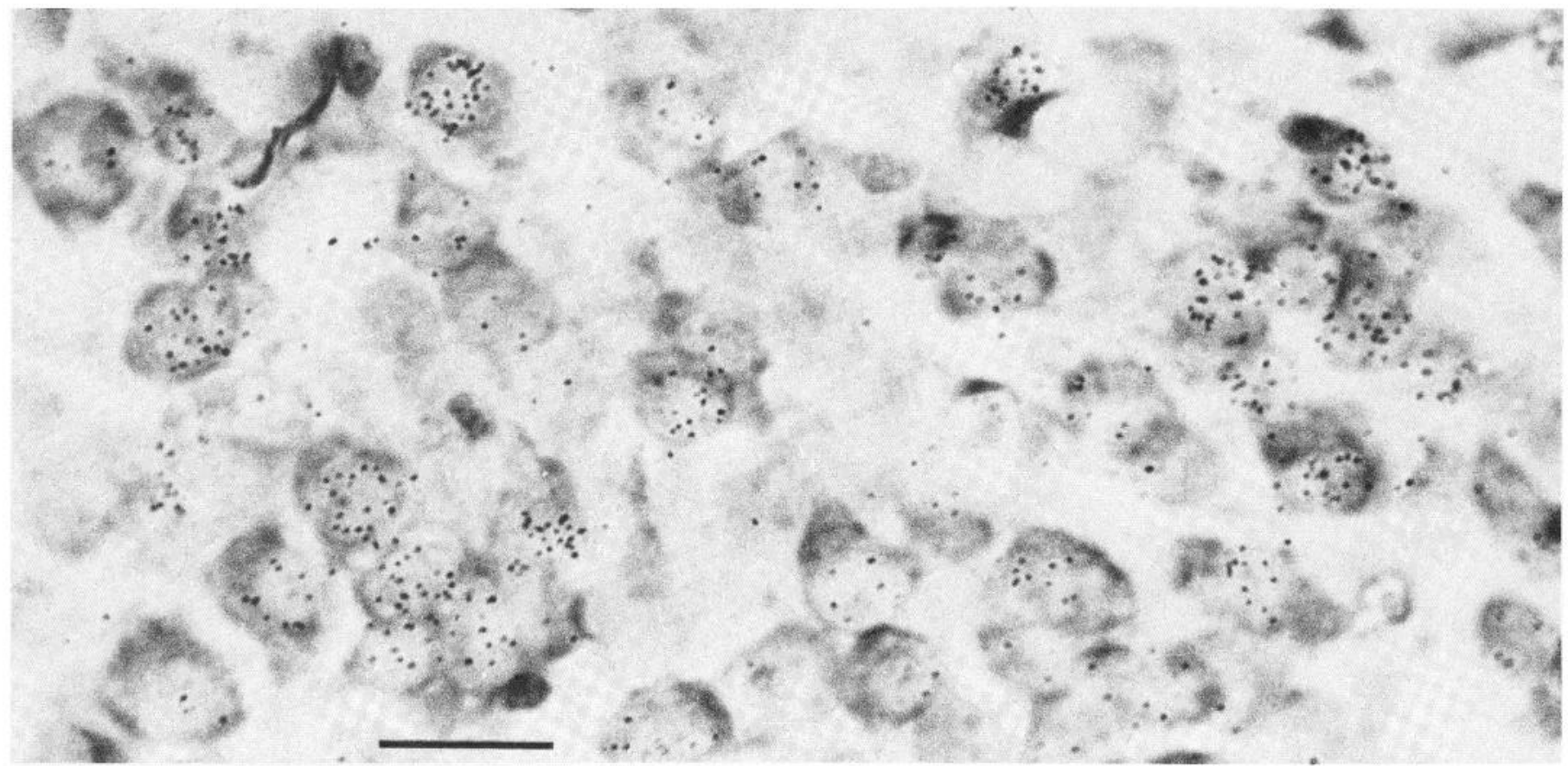

Figure 1. Survival of grafted neurons was confirmed in all cases by tritiated thymidine autoradiography. Note clusters of silver grains over cell nuclei. Thionin counterstained. The bar represents $25 \mu$.

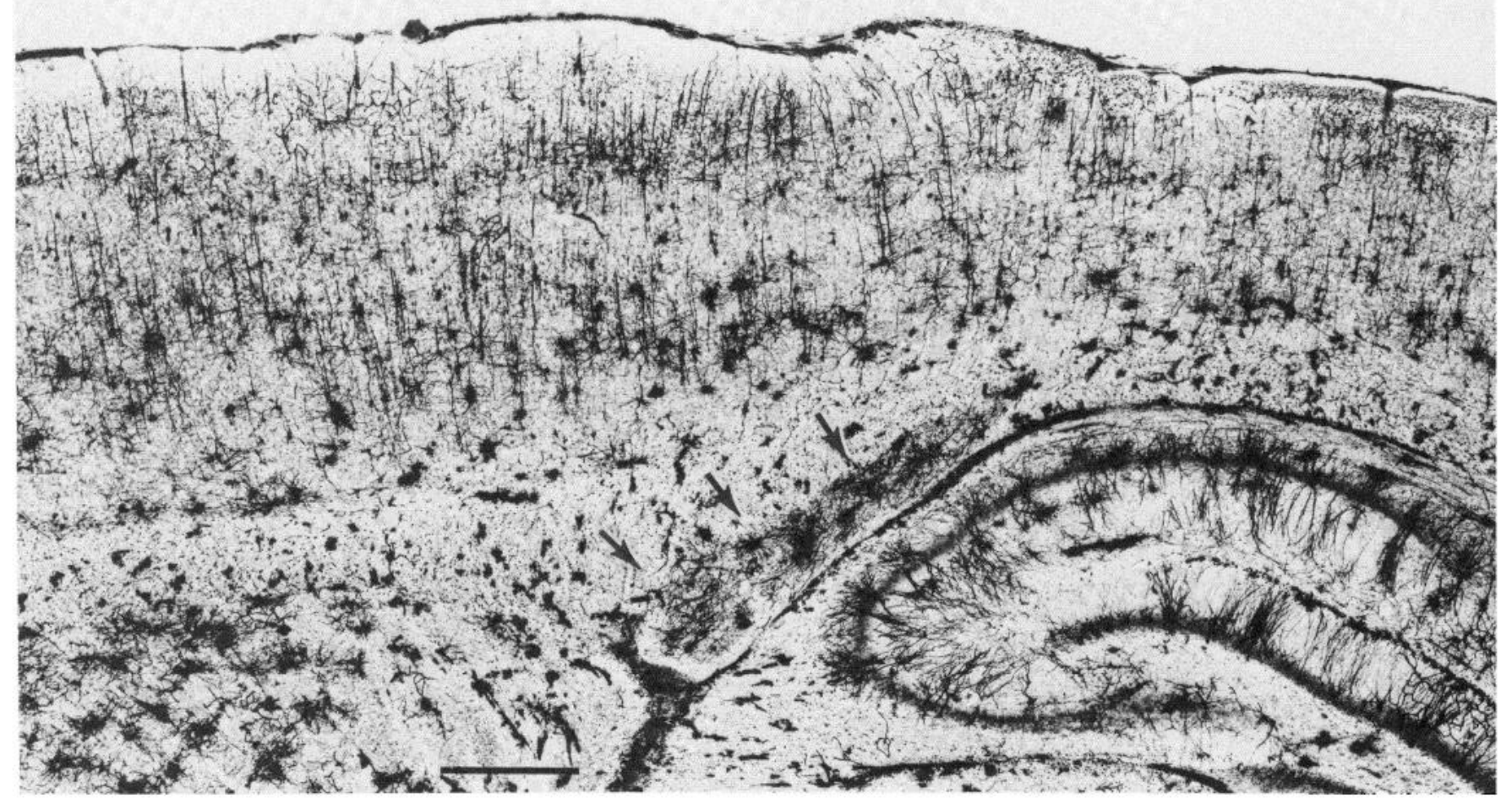

Figure 2. Grafts were commonly found protruding through the subcortical white matter into the lateral ventricle though remaining in continuity with the host cortex. In this sagittal section stained with the Golgi Cox method and counterstained with thionin, a graft can be seen overlying the fornix. Anterior is to the left. Figure 5 shows similarly positioned grafts in frontal section. The bar represents $500 \mu$.

helpful in determining the morphology of grafted dissociated neurons, although mature but misaligned pyramidal cells just below the pia mater could have been of graft origin.
Many features reminiscent of normal cortical structure can be seen in the solid grafts (Jaeger and Lund, 1980a, b, 1981). Acellular regions resembling molecular layers and regions containing fiber bundles break up regions of 
neuronal cells. Golgi staining demonstrated that both pyramidal and nonpyramidal cells were found in this region, although their shape was frequently distorted. No preferential positioning or lamination of these different cells were seen with respect to each other, although some pyramidal cells had apical dendrites oriented toward molecular zones (Fig. 4). These had the most recognizable pyramidal morphology, although pyramidal cells throughout the graft had many typical aspects of pyramidal cells such as large "apical" dendrites, spines, and recurrent axonal collaterals (see Fig. $4 B$ ). Nonpyramidal cells were of spiny and aspiny types (Fig. $4 B$ ), but axons were not impregnated well enough to allow identification of particular interneuron classes.

The organization of suspension grafts depended on the size of the aggregate. One feature typical of most aggre-
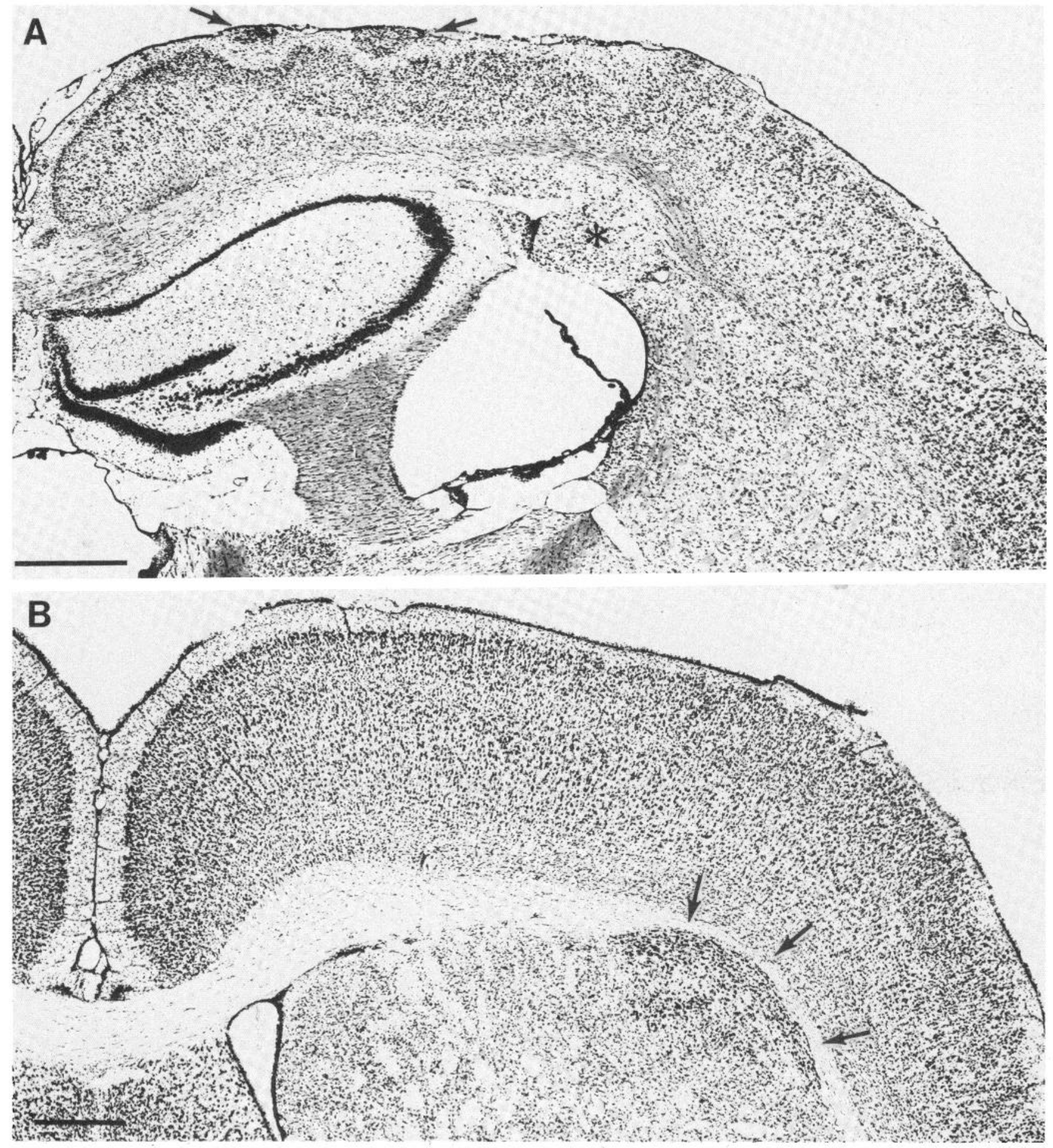

Figure 3. Gross morphology of grafts. Bars represent $500 \mu$. A, Dissociated cells of grafts have reaggregated as several small clumps on the surface of the host cortex which shows a severe effect of MAM. The asterisk indicates an ectopic island typical of MAM-treated animals. Luxol Fast Blue stain. B, A solid graft, indicated by arrows, is wedged between the host cortical white matter and striatum. This host shows only a mild MAM effect. Thionin stained. 

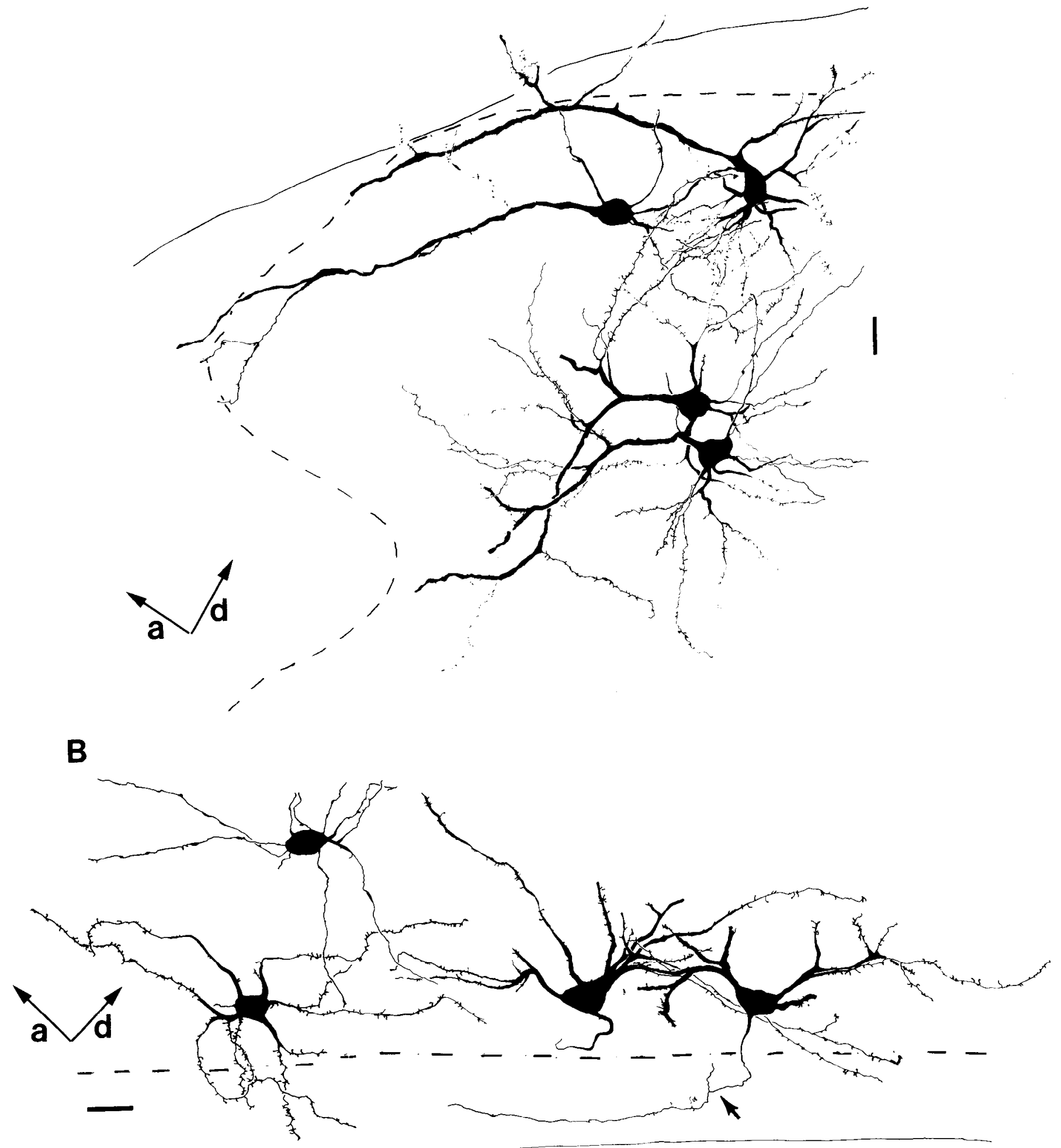

Figure 4. Camera lucida tracings of neurons from the graft shown in Figure 2. Solid lines indicate the border of the graft. Dotted lines indicate intragraft boundaries between cellular and acellular zones. $a$, anterior; $d$, dorsal. The $b a r$ represents $20 \mu$. $A$, Four pyramidal neurons located near the anterior tip of the graft. Note the orientation of the apical dendrites toward the cellsparse "molecular zone." $B$, Four cells near ventral side of graft. Two toward the right appear to be distorted pyramidal neurons. The arrrow indicates an axon which appears to bend back toward the graft. The two cells toward the left are nonpyramidal neurons.

gates was the presence of an acellular central area. In Luxol Fast Blue-stained sections, a bundle of myelinated fibers was sometimes seen traversing this central core (e.g., Fig $3 A$ ). Blood vessels were seen in all grafts.
Graft-host connections. To examine fiber outgrowth from grafts into areas of the host brain, injections of retrogradely transported tracers were made into contralateral cortex, thalamus, and spinal cord, since these are 


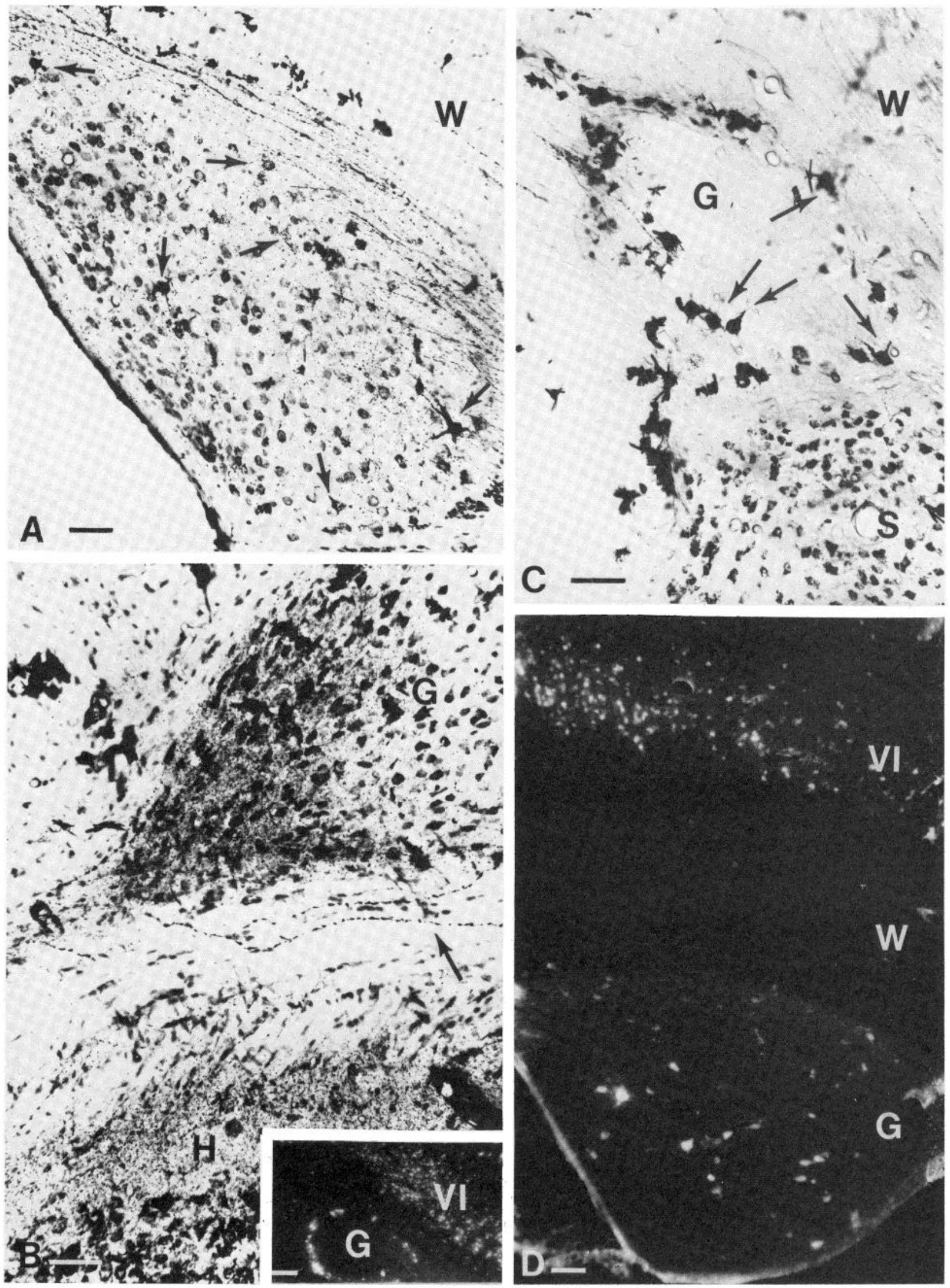

Figure 5. Frontal sections through grafts in which connections were examined. All of these grafts lie within the cortical white matter at some point, and some protrude into the ventricle. Medial is to the left and dorsal is up. Bars represent $50 \mu$. A, An injection of HRP in the cortex contralateral to this suspension graft has resulted in retrogradely labeled cells throughout the graft, a few of which are indicated by arrows. Fine terminal labeling can be seen on the lateral side. $B$, An injection of $\mathrm{HRP}$ was made into the cortex contralateral to this solid graft $(G)$. Labeled fibers (arrows) can be seen entering the graft, as well as in the underlying hippocampal formation $(H)$. A spray of terminal labeling occupies the medial corner of the graft. Retrogradely labeled 
three of the major projection sites of normal sensorimotor cortex. Anterogradely transported HRP provided information on host projections to grafts. Since the goal of this study was to determine the absence or presence of projections and not precise topography, the injection sites were generally large.

The data for solid and suspension grafts will be combined since there was no obvious difference in the pattern of their connections.

Graft cells sent axons to the opposite cortex. After contralateral injections of retrograde tracers, labeled cells were seen in five cases (Fig. 5A). The number of labeled graft cells observed ranged from two in one case to well over 100 in another case. Labeled cells tended to occur in small clusters of three or four cells, although clusters occurred in different areas throughout the graft. The greatest numbers of retrogradely labeled cells occurred when the graft was wedged within the subcortical white matter close to the corpus callosum, but even grafts at the surface of the cortex often contained some labeled cells. In all cases, the host cortex adjacent to the graft contained retrogradely labeled cells, too. Graft neurons tended to be less heavily labeled than nearby host neurons.

In those cases where anterograde HRP labeling was also identifiable, the number of labeled axons entering the graft was very small. Terminal labeling was best seen in deep grafts and was restricted to parts of the graft in the vicinity of the adjacent corpus callosum. These often did not correspond to areas in which retrogradely labeled cells were seen (Fig. $5 B$ ).

Graft cells also sent axons out of the cortex, to the thalamus and spinal cord. Again, the number of retrogradely labeled cells was small compared to the total number of ${ }^{3} \mathrm{H}$-labeled cells in the graft. In all five cases of spinal cord injections, the number of labeled cells was less than 15 . With injections into thalamus in seven cases, the number of labeled cells ranged from five in one case to several hundred in another. In four cases, animals received injections of different retrograde tracers in these two sites. In two cases, HRP was injected into the thalamus and $\mathrm{FB}$ into the spinal-medullary junction. Cells labeled with one or another of these tracers were seen in the graft (Fig. 5, $C, D$, and $B$, inset). In the other two cases FB was injected into the thalamus and NY into the spinal cord. Cells were labeled from both sites, although none were double labeled. Absence of double labeling from these two sites is also the case in the normal intact adult brain (Catsman-Berrevoets and Kuypers, 1981). As in the case of callosally projecting cells, cells labeled retrogradely from the thalamus frequently occurred in small clusters throughout the graft. In three cases, one of which was an aggregate of cells from a suspension graft (Fig. 5B, inset), the labeled neurons were clustered along the periphery of the graft, although not continuous with labeled neurons in layer VI of the host cortex (Fig. 5C).

In those cases where anterograde labeling of thalamocortical axons with HRP was identifiable in the host cortex, no terminal labeling was observed within the graft, although in one case a bundle of fibers passed through the graft. In one case of a small injection of HRP apparently limited to the dorsal column nuclei, retrogradely labeled cells were not found in the solid graft, which was, however, separated from the host cortex by pia mater.

In all cases where the morphology of a retrogradely labeled cell could be identified in host cerebral cortex or graft, it was pyramidal in form.

\section{Discussion}

These data demonstrate that the cortex of a MAMtreated rat will accept grafted fetal tissue and that this will remain viable for at least 6 months. Grafts did not "reconstitute" the cortex in the sense of forming missing layers, since graft cells tended to remain as discrete clumps within the host brain. Nor did grafts enable the cortex to replace those connections usually provided by cells of missing layers, although significant axonal outgrowth from grafts could be demonstrated. Ingrowth of fibers from the host, although never considerable, could be demonstrated for callosal fibers but not for thalamocortical fibers.

Although grafts did not form layers upon the host cortex, they did develop a crude internal organization with aspects of cortical structure. The most consistent feature, both in large suspension aggregates and in solid grafts, was the formation of a cell-sparse area similar to a molecular layer. The appearance of a molecular layer, as well as the formation of a rudimentary white matter, has been described in other studies where pieces of cortex (although not cell suspensions) have been transplanted to heterotopic and homotopic locations (Jaeger and Lund, 1980a, b; Das et al., 1980). However, the laminated organization described in some studies (Das et al., 1980) was not seen in our material, which was serially sectioned and every section examined. This may reflect differences in the size of the cortical piece transplanted and the constraints of the space in which it grows. The cellular organization of suspension grafts was more similar to that described for cultured aggregates of cortical neurons (Garber et al., 1980) than to suspension grafts from other brain areas (Schmidt et al., 1981). This seems to indicate that certain characteristics of cellular organization of different brain areas arise from properties intrinsic to the cells of those areas.

Axons of grafted neurons grew into three host brain

cells were also present in this graft, although not in the region pictured. $C$, A large injection of HRP which included the thalamus and a portion of the globus pallidus has labeled a ring of cells around the periphery of a piece of solid graft $(G)$, some of which are indicated by arrows. Label can be seen in the host striatum. $D$, Cells labeled retrogradely from the thalamus with FB can be seen within this solid graft $(G)$ which protrudes into the ventricle, as well as in the host corticothalamic neurons of layer VI overlying the white matter $(W)$, following an injection into the thalamus. The inset shows the results from a similar thalamic injection of FB in which a ring of neurons is retrogradely labeled on the periphery of an aggregate of a suspension graft $(G)$ as well as in layer VI of the cortex. The bar represents $100 \mu$. 
areas which are normally innervated by sensorimotor cortex: contralateral cortex, thalamus, and spinal cord. In the MAM-treated rat lacking layers II to IV, projections to thalamus and spinal cord are intact (Jones et al., 1982), since these originate from the surviving cells of layers VI and V, respectively. Graft cells, then, duplicated existing projections, and did not form only those projections which the host lacked. Graft cells did, however, project to the contralateral cortex; these axons traveled within the attenuated corpus callosum of the MAM-treated host and did not reform the entire corpus callosum. There was no obvious indication that the more severe the host callosal defect, the greater the number of callosally projecting graft neurons; comparable numbers of callosally projecting graft neurons can be seen in grafts to normal hosts (M. K. Floeter and E. G. Jones, unpublished cases). This suggests that there is no selective tendency for graft cells to form developmentally deficient host projections.

Projections of homotopically grafted pieces of cerebral cortex have not been previously described. Three features seem to be common to all the grafts that had demonstrable projections into sites within the host brain. First, the grafts are contiguous at some portion with a region of the host brain which also contains cells projecting to the same site; individual cells projecting out of the graft do not, however, tend to cluster at the border of contiguity. For this reason and because of the discreteness of the grafts and the high proportion of $\left[{ }^{3} \mathrm{H}\right]$ thymidine-labeled cells in them, it is unlikely that the projecting cells represent host neurons that have migrated into the graft. A second consistent feature is that grafts buried within or contacting the host white matter contained greater numbers of cells projecting to any particular host location than more superficially placed grafts. The final point is that when the morphology of projecting neurons could be identified from the HRP labeling, all were pyramidal neurons, suggesting that, as in normal intact cortex (Wise and Jones, 1977) and the MAM-treated cortex (Jones et al., 1982), these are the projection neurons.

It is likely that each graft contained cells that projected to a number of different sites, since from any single injection site, the number of retrogradely labeled cells was small relative to the number of cells within the graft. Also, in four cases where injections of combinations of different colored fluorescent dyes and HRP were made in the spinal cord and in the thalamus, cells were retrogradely labeled from both sites. It needs to be determined whether each graft contains a small number of neurons sending axons randomly to many brain regions.

A further question is whether axons of graft cells follow axons of cells in existing pathways of the host (e.g., Bate, 1976) since grafts with demonstrable projections were close to similarly projecting efferent axons of the host cortex.

A third question is whether grafted neurons project to the same targets in hosts as they would have projected to in the donor. At the age at which the fetal tissue was removed for grafting, corticospinal and corticothalamic cells have been born, and many of them have sent axons as far as the internal capsule (Schreyer and Jones, 1982). It is not yet clear whether graft cells projecting to spinal cord and thalamus are derived from these or, atypically, from cells which would have formed different projections in the animal from which they were taken.

Ingrowth of axons from host commissural neurons was quite sparse and usually occurred only in areas of the graft bordering the corpus callosum. Thalamocortical axons were not observed innervating grafts, and further experiments are needed to determine the reason for this.

Although reconstitution of the MAM-damaged cortex by grafts did not occur, these data show that cortical grafts can form some of the normal connections of the brain area into which they are transplanted. The absence of certain populations of host cells does not appear to influence grafted neurons to take over connections of the missing cells exclusively. Instead, graft cells reproduce some of the variety of connections of intact cortex and suggest several factors involved in target finding by cortical neurons that can be investigated further in the future.

\section{References}

Bate, C. M. (1976) Pioneer neurones in an insect embryo. Nature 260: 54-56.

Bentivoglio, M., H. G. M. Kuypers, C. E. Catsman-Berrevoets, H. Loewe, and O. Dann (1980) Two new fluorescent retrograde neuronal tracers which are transported over long distances. Neurosci. Lett. 18:25-30.

Björklund, A., and U. Stenevi (1977) Reformation of the severed septo hippocampal cholinergic pathway in the adult rat by transplanted septal neurons. Cell Tissue Res. 185: 289 302.

Björklund, A., and U. Stenevi (1979) Reconstruction of the nigrostriatal dopamine pathway by intracerebral nigral transplants. Brain Res. 177: 555-560.

Björklund, A., U. Stenevi, and N. Svengaard (1976) Growth of transplanted monoaminergic neurones into the adult hippocampus along the perforant path. Nature 262: 787-790.

Catsman-Berrevoets, C. E., and H. G. M. Kuypers (1981) A search for corticospinal collaterals to thalamus and mesencephalon by means of multiple retrograde fluorescent tracers in cat and rat. Brain Res. 218: 15-33.

Das, G. D. (1975) Differentiation of dendrites in the transplanted neuroblasts in the mammalian brain. Adv. Neurol. 12: $181-199$

Das, G. D. (1982) Extraparenchymal neural transplants: Their cytology and survivability. Brain Res. 241: 182-186.

Das, G. D., B. H. Hallas, and K.G. Das (1980) Transplantation of brain tissue in the brain of rat. I. Growth characteristics of neocortical transplants from embryos of different ages. Am. J. Anat. 158: 135-145.

De Olmos, J., H. Hardy, and L. Heimer (1978) The afferent connections of the main and the accessory olfactory bulb formations in the rat: An experimental HRP study. J.Comp. Neurol. 181: 213-244.

Dunnett, S. B., A. Björklund, U. Stenevi, and S. D. Iversen (1981) Behavioral recovery following transplantation of substantia nigra in rats subjected to 6 OHDA lesions of the nigrostriatal pathway. I. Unilateral lesions. Brain Res. 215: 147-161.

Dunnett, S. B., W. C. I.ow, S. D. Iversen, U. Stenevi, and A. Bjorklund (1982) Septal transplants restore maze learning in rats with fornix-fimbria lesions. Brain Res. 251: 335-348.

Floeter, M. K., L. Yurkewicz, and E. G. Jones (1982) Cortical transplant connections with host brains damaged in utero. Soc. Neurosci. Abstr. 8: 759.

Garber, B. B., P.R. Huttenlocher, and L. H. M. Larramendi 
(1980) Self assembly of cortical plate cells in vitro within embryonic mouse cerebral aggregates. Golgi and electron microscopic analysis. Brain Res. 201: 255-278.

Gash, D., J. R. Sladek, Jr., and C. D. Sladek (1980) Functional development of grafted vasopressin neurons. Science 210: 1367-1369.

Jaeger, C. B., and R. D. Lund (1980a) Transplantation of embryonic occipital cortex to the brain of newborn rats: An autoradiographic study of transplant histogenesis. Exp. Brain Res. 40: 265-272.

Jaeger, C. B., and R. D. Lund (1980b) Transplantation of embryonic occipital cortex to the tectal region of newborn rats: A light microscopic study of organization and connectivity of the transplants. J. Comp. Neurol. 194: 571-597.

Jaeger, C. B., and R. D. Lund (1981) Transplantation of embryonic occipital cortex to the brain of newborn rats: A Golgi study of mature and developing transplants. J. Comp. Neurol. 200: 213-230.

Johnston, M. V., and J. T. Coyle (1979) Histological and neurochemical effects of fetal treatment with methylazoxymethanol on rat neocortex in adulthood. Brain Res. 170: 135155.

Jones, E. G., K. L. Valentino, and J. W. Fleshman, Jr. (1982) Adjustment of connectivity in rat neocortex after prenatal destruction of precursor cells of layers II-IV. Dev. Brain Res. 2: 425-431.

Krieger, D. T., M. J. Perlow, M. J. Gibson, T. F. Davies, E. A. Zimmerman, M. Ferin, and H. M. Charlton (1982) Brain grafts reverse hypogonadism of gonadotropin releasing hormone deficiency. Nature 298: 468-471.

Kromer, L. F., A. Björklund, and U. Stenevi (1980) Innervation of embryonic hippocampal implants by regenerating axons of cholinergic septal neurons in the adult rat. Brain Res. 210: $153-171$.

LeGros Clark, W. E. (1940) Neuronal differentiation in implanted foetal cortical tissue. J. Neurol. Psychiatry 3: 262272.

Lewis, E. R., and C. W. Cotman (1982) Mechanism of septal lamination in the developing hippocampus analyzed by outgrowth of fibers from septal implants. J. Neurosci. 2: 66-77.

Low, C. L., P. R. Lewis, S. T. Bunch, S. B. Dunnett, S. R. Thomas, S. D. Iversen, A. Björklund, and U. Stenevi (1982) Function recovery following neural transplantation of embryonic septal nuclei in adult rats with septohippocampal lesions. Nature 300: 260-262.

Lund, R. D., and A. R. Harvey (1981) Transplantation of tectal tissue in rats. I. organization of transplants and pattern of distribution of host afferents within them. J. Comp. Neuronal. 201: 191-209.

Lund, R. D., and S. D. Hauschka (1976) Transplanted neural tissue develops connections with host rat brain. Science 193: $582-584$.

Oblinger, M. M., and G. D. Das (1982) Connectivity of neural transplants in adult rats: Analysis of afferents and efferents of neocortical transplants in the cerebellar hemisphere. Brain Res. 249: 31-49.

Oblinger, M. M., B. H. Hallas, and G. D. Das (1980) Neocortical transplants in the cerebellum of the rat: Their afferents and efferents. Brain Res. 189: 228-232.

Paul, J. (1975) Cell and Tissue Culture, Ed. 5, Churchill Livingstone, New York, pp. 367-368.

Perlow, M. J., W. J. Freed, B. F. Hoffer, A. Seiger, L. Olson, and R. J. Wyatt (1979) Brain grafts reduce motor abnormalities produced by destruction of nigrostriatal dopamine system. Science 204: 643-646.

Puck, T. T., S. J. Cieciura, and A. Robinson (1958) Genetics of somatic mammalian cells. III. Long-term cultivation of euploid cells from human and animal subjects. J. Exp. Med. 108: 945-956.

Rethelyi, M. (1972) Cell and neuropil architecture of the intermediolateral (sympathetic) nucleus of cat spinal cord. Brain Res. 46: 203-213.

Schmidt, R. H., A Björklund, and U. Stenevi (1981) Intracerebral grafting of dissociated CNS suspensions: A new approach for neuronal transplantation to deep brain sites. Brain Res. 218: 347-356.

Schreyer, D. J., and E. G. Jones (1982) Growth and target finding by axons of the cortico spinal tract in prenatal and postnatal rats. Neuroscience 7: 837-853.

Smith, L., and F. Ebner (1982) The fine structure of embryonic neocortex transplanted into adult mouse cortex. Soc. Neurosci. Abstr. 8: 865.

Van der Loos, H. (1956) Une combinaison de deux vieilles methodes histologiques pour le systeme nerveux central. Monatsschr. Psychiatr. Neurol. 132: 330-334.

Welker, C. (1971) Microelectrode delineation of fine grain somatotopic organization of SmI cerebral neocortex in albino rat. Brain Res. 26: 259-275.

Wise, S. P., and E. G. Jones (1976) The organization and postnatal development of the commissural projection of the rat somatic sensory cortex. J. Comp. Neurol. 168: 313-344.

Wise, S. P., and E. G. Jones (1977) Cells of origin and terminal distribution of descending projections of the rat somatic sensory cortex. J. Comp. Neurol. 175: 129-157. 